\title{
A VIDA POR UM FIO: PERCEPÇÕES SOBRE O IMPLANTE DE MARCA-PASSO CARDÍACO PERMANENTE
}

\author{
Life by a Thread: Perceptions about Permanent Cardiac Pacemaker Implantation \\ La Vida por un Hilo: Percepciones sobre el Implante del Marcapaso Cardíaco Permanente
}

La Vie par un Fil: Aperçus sur L'implantation d'un Stimulateur Cardiaque Permanent

Psicóloga, Faculdades Integradas FAFIBE.

Alba Regina Nemer Bergmann

Psicóloga, Faculdades Integradas FAFIBE.

Laura Vilela e Souza

Doutora em Psicologia, Professor Adjunto da Universidade Federal do Triângulo Mineiro, Uberaba, MG.

Fabio Scorsolini-Comin

Pós-doutorando em Psicologia, Professor Adjunto da Universidade Federal do Triângulo Mineiro, Uberaba, MG.

Manoel Antônio dos Santos

Professor Associado 3 da Faculdade de Filosofia, Ciência e Letras de Ribeirão Preto, Universidade de São Paulo. Bolsista de Produtividade em Pesquisa do CNPq, nível 1B.

Recebido em: 31/12/2014 / Revisado em: 21/09/2015 / Aceito em: 23/11/2015

\section{Resumo}

Este estudo descritivo e exploratório teve como objetivo examinar as percepções sobre o uso de marca-passo cardíaco permanente. Como estratégia metodológica, utilizou-se o estudo de caso na perspectiva psicanalítica. O corpus de análise foi composto pela estratégia da história de vida focal, operacionalizada por entrevista em profundidade. Foram identificadas as seguintes percepções: choque ao receber o diagnóstico, medo de morrer durante a cirurgia, implante do marca-passo como tábua de salvação, satisfação com o procedimento e preocupação constante dos familiares com o bem-estar da paciente. Os dados sugerem a necessidade de apoio psicológico ao paciente desde o momento do implante do dispositivo cardíaco. Nesse contexto, a escuta qualificada do inconsciente possibilita avançar na compreensão psicodinâmica de seu padecimento.

Palavras-chave: marca-passo; arritmia; psicossomática; estudo de caso.

\section{Abstract}

This descriptive and exploratory study aimed to examine perceptions about the use of permanent cardiac pacemaker. As a methodological strategy, the case study was used in the psychoanalytic perspective. The corpus of analysis was composed by the strategy of the focal life history, operationalized by an in-depth interview. The following perceptions were identified: shock after getting the diagnosis, fear of dying during surgery, implantation of the pacemaker as a lifeline, satisfaction with the procedure, and constant concern of the family with the patient's well-being. The data suggest the need for psychological support to the patient from the moment of implantation of the cardiac device. In this context, the qualified listening of the unconscious allows to advance in the psychodynamic understanding of its suffering.

Keywords: pacemaker; arrhythmia; psychosomatic; case study. 


\section{Resumen}

Este trabajo descriptivo y de exploración tuvo como objetivo examinar las percepciones sobre el uso de marcapasos cardíaco permanente. Como estrategia metodológica se utilizo el estudio de caso, bajo la perspectiva psicoanalítica. El corpus del análisis fue compuesto por la estrategia de la historia de vida focal, llevada a cabo por entrevista en profundidad. Fueron identificadas las siguientes percepciones: choque al recibir el el diagnóstico, miedo de morir en la cirugía, implante del marcapaso como tabla salva-vidas, satisfacción con el procedimiento y preocupación constante de los familiares con el bienestar del paciente. Los datos sugieren la necesidad de apoyo psicológico al paciente desde el momento de la implantación del dispositivo cardíaco. En este contexto, la escucha cualificada del inconsciente posibilita avanzar en la comprensión psico-dinámica de su padecimiento.

Palabras clave: marcapaso; arritmia; psico-somática; estudio de caso.

\section{Résumé}

Cette étude descriptive exploratoire a l'objectif d'examiner les perceptions quant à l'utilisation d'un stimulateur cardiaque permanent. L'etude de cas, dans la perspective psychanalytique, a été la stratégie méthodologique utilisé. Le corpus d'analyse a été composée par la stratégie de l'histoire de la vie focale, opérationnalisée par des entretiens en profondité. Les idées suivantes ont été identifiés : choc après avoir reçu le diagnostic, la peur de mourir pendant la chirurgie, l'implant de stimulateur cardiaque comme ligne de vie, satisfaction avec la procédure et constante préoccupation de la famille en ce qui concerne le bien-être du patient. Les données suggèrent la nécessité d'un soutien psychologique pour le patient dès le moment de l'implantation du dispositif. Dans ce contexte, l'écoute qualifié de l'inconscient permet d'avancer dans la compréhension psychodynamique de vos souffrances.

Mots-clés: stimulateur cardiaque; arythymie ;psychosomatique; étude de cas.

Ao longo das últimas quatro décadas, o procedimento de estimulação cardíaca artificial teve significativo avanço tecnológico. O marca-passo cardíaco é um moderno sistema de estimulação artificial do coração que transmite estímulos de natureza elétrica por meio de um gerador de pulsos e um eletrodo com o propósito de substituir a "pilha natural" do coração (Andrade, 2001; Aredes et al., 2010). Os dispositivos cardíacos eletrônicos implantáveis (DCEI) promovem conforto e bemestar, oferecendo ao paciente maior segurança nos cenários de urgência. Desse modo, seu uso se torna obrigatório para a manutenção da vida e prevenção da morte súbita em pacientes com cardiopatias graves (Benassi, Valero, \& Jurado, 2009; Brasil \& Cruz, 2000; Falcão, 2004; Sardinha, Nardi, \& Zin, 2009). Tal uso segue as diretrizes preconizadas pela Sociedade Brasileira de Cardiologia (Martinelli Filho, Zimerman, Lorga, Vasconcelos, \& Rassi, 2007).

A evolução no conhecimento eletrofisiológico, associada ao desenvolvimento tecnológico dos aparelhos e ao avanço nos métodos diagnósticos, tornou o implante de marca-passo definitivo um procedimento seguro, que pode levar o indivíduo a ter maior sobrevida com qualidade. Essa sobrevida, doravante, dependerá mais da doença de base do que do distúrbio elétrico devidamente tratado. Na atualidade, os aparelhos oferecem diversos modos de funcionamento, com parâmetros programáveis, capazes de gerar um estímulo elétrico confiável e, por vezes, fisiológico (Brasil \& Cruz, 2000).

O procedimento de implantação do marca-passo geralmente é rápido, pois não requer uma cirurgia aberta do coração. A cirurgia é realizada com anestesia local. A maior parte dos pacientes recebe alta em 24 horas. É feita uma incisão na pele, na porção superior do tórax, onde são introduzidos um ou dois cabos-eletrodos através de uma veia até o coração. Os eletrodos são conectados ao marca-passo, o qual é programado pelo cirurgião de acordo com as necessidades do paciente. O dispositivo é introduzido debaixo da pele e, em seguida, a incisão é fechada.

Segundo Leão (2001), a sobrevida com qualidade do paciente que recebeu o implante é difícil de ser caracterizada ou mensurada. Entretanto, essa estimativa deve ser buscada na tentativa de avaliar as repercussões pessoais do procedimento terapêutico, pois o tratamento é implementado não apenas para prolongar a vida, mas para melhorá-la significativamente. Hoje, a estimulação elétrica artificial não é considerada apenas mais uma forma de salvar a vida de doentes com bloqueios cardíacos; é um modo de correção das alterações do ritmo e do sincronismo atrioventricular, que pode auxiliar na manutenção de estilos de vida, permitindo a realização das atividades diárias. Sua aplicação requer, porém, certos cuidados, como a avaliação periódica do sistema e o conhecimento, pelo paciente, das possíveis fontes de interferência, por se tratar de um dispositivo com componentes eletrônicos.

Há, portanto, necessidade de acompanhamento do portador de marca-passo para garantir a manutenção de seu bemestar. De acordo com Carroll (2014), o isolamento social, o estado psicológico e a necessidade de receber informações são 
componentes que devem ser considerados no processo de recuperação de um procedimento cardiovascular. Como prótese inerte, o marca-passo em si não implica em qualquer limite de atividade física, "permitindo o retorno do paciente à sua vida profissional, familiar e esportiva, já que o objetivo principal do tratamento com marca-passo é resgatar a qualidade de vida do paciente" (Leão, 2001, p. 75). Apesar disso, há que se considerar que o uso de qualquer prótese tende a causar reações e manifestações emocionais, uma vez que altera o estilo de vida das pessoas. $\mathrm{O}$ aprimoramento da condição física nem sempre significa melhora análoga no bem-estar psicológico dos pacientes, por isso é importante avaliar o ajustamento do paciente às limitações e possibilidades oferecidas pelo fato de ter de conviver permanentemente conectado a um mecanismo biomecânico.

Nessa direção, ainda são escassos os estudos dedicados a apreender as percepções e os significados que o paciente atribui ao implante cardíaco. Segundo Magnani, Oliveira e Gontijo (2007), a indicação para o uso do marca-passo é percebida de modo diferente pelas pessoas, pois "o corpo não é somente uma entidade biológica, mas um fenômeno cultural e histórico" (p. 1626). Esses mesmos autores apontam que o sentido inicial dado para o uso do mecanismo é o de possuir um coração doente, no qual o estímulo vital (biológico, natural, saudável) será secundário ao estímulo artificial (fornecido pelo marca-passo). Assim, o paciente vivencia essa facticidade entendendo que o funcionamento de seu corpo está totalmente dependente de um aparelho, inclusive para a efetivação de funções vitais até então realizadas naturalmente, sem grandes esforços e sem ter a atenção focalizada nos ritmos de funcionamento de uma máquina.

A relação corpo-prótese é complexa e repercute profundamente na imagem corporal do paciente. A princípio, após absorver o impacto da introdução do aparelho, a pessoa pode sentir-se marcada, tanto física quanto psicologicamente, tendo que ressignificar sua rotina e reorganizar suas ações e pensamentos. Dentre as mudanças de comportamento evidenciadas após a colocação do marca-passo, segundo a literatura, figuram: a resistência dos pacientes à sua implantação; a negação da necessidade de seu uso contínuo; a rejeição do viver com o mecanismo; a desconfiança em relação à sua resolutividade; o medo permanente da morte; a ideia de um coração fraco que tornará a vida dependente de um aparelho; o significado atribuído ao coração como um órgão representativo de aspectos emocionais profundos; a busca de uma explicação para sua condição adversa de saúde na tentativa de dar um sentido para o ocorrido; baixa autoestima e depressão, entre outras possíveis manifestações psicológicas (Leosdottir et al., 2006; Magnani et al., 2007; Newall, Lever, Prasad, Hornabrook, \& Larsen, 2007; Willians, Young, Nikoletti, \& McRae, 2004).

Waltkins e Brown (2002) aponta a ruminação - entendida como preocupações e pensamentos que ficam excessivamente focados nos sintomas ou nas suas consequências - como componente importante nas manifestações de depressão e ansiedade detectadas nesses pacientes. Todavia, não se sabe se esse é um processo reativo à colocação do marca-passo ou se está relacionado à comorbidades psíquicas preexistentes.

Após exame da literatura da área pode-se perceber que, dentre as pesquisas que abordam as vivências emocionais dos portadores de marca-passo, predominam os estudos que objetivam conhecer a qualidade de vida antes e depois da sua implantação. Van-Eck et al. (2008) buscaram identificar a relação entre uso dele e qualidade de vida em um maior número de pacientes e de maneira mais sistemática do que estudos anteriores. Esses autores constataram que, mesmo antes da colocação do marca-passo, já existia uma depreciação da qualidade de vida nessas pessoas em comparação com a população geral. Esse declínio é justificado pelos prejuízos do déficit cardíaco que motivou a colocação do dispositivo. Tais resultados levaram os autores a chamarem a atenção para a necessidade de que os médicos diminuam o tempo de espera entre o diagnóstico e o procedimento cardíaco.

Para além dos aspectos médicos, como mencionado, há fatores psicológicos que perpassam tanto o diagnóstico da doença cardíaca, quanto o procedimento cirúrgico, sem contar o desconforto de conviver com um dispositivo biomecânico acoplado perenemente ao próprio corpo. Além dos sentimentos de ameaça à vida incrementarem a sensação de vulnerabilidade e insegurança do paciente, o uso do aparelho e a imprevisibilidade de seu funcionamento geram incômodo e impõem uma série de cuidados que limitam o cotidiano, exigindo ajustamento da rotina e alterações no estilo de vida. Compreender o alcance e significado dessas vicissitudes exige lançar mão de um quadro teórico que nos permita compreender, de forma mais abrangente, a situação emocional na qual se encontra o doente.

A compreensão psicanalítica do doente orgânico não intenciona "categorizar" a conduta do indivíduo, pelo contrário, busca compreendê-la em sua dinâmica psíquica e pulsional, uma vez que todo indivíduo utiliza de recursos defensivos para lidar com seus conflitos psíquicos. Vale lembrar que a teoria psicanalítica surgiu justamente no esforço de relacionar o sintoma e seu representante mental, quando Freud (1915/1990a) notou que pacientes histéricas se abstinham de sua sintomatologia quando se encontravam em estado alterado de consciência. Com os avanços da teoria e da clínica, o tratamento baseado na hipnose e nos estados de transe deram lugar ao método catártico e à psicoterapia propriamente dita. Desde então, inúmeros relatos e estudos se seguiram, ampliando o conhecimento científico sobre as doenças e sua implicação biopsicossocial (Oliveira-Cardoso, Santos, Mastropietro, \& Voltarelli, 2009). Atualmente, há um reconhecimento crescente da importância de investigar os fatores psicológicos associados aos agravos à saúde, acompanhando a definição ampliada de saúde proposta 
pela Organização Mundial da Saúde.

A relação entre Psicanálise e doenças cardíacas é delineada por Mello Filho (1992) ao evidenciar que as emoções repercutem no funcionamento do coração como fenômenos subjetivos para as quais o sujeito atribui uma representação simbólica, percebendo-os como uma manifestação externa. Para esse autor, a vida psíquica constitui-se de uma somatória de experiências atuais e passadas, registradas de forma singular por cada indivíduo, e sentidas de acordo com as contradições e censuras que constituem cada organização de personalidade, tanto na esfera consciente como inconsciente. Nessa direção, a teoria psicanalítica, como método de escuta e de entendimento do sujeito do inconsciente, fornece um rico instrumental para a compreensão dos fenômenos psíquicos que emergem na experiência de implante do marca-passo. Dentre as repercussões psíquicas mais comumente encontradas, podemos mencionar as alterações na percepção que o sujeito tem de si mesmo, dos outros e do mundo em que se insere ao ver-se na inusitada condição de conviver com um dispositivo implantado em seu corpo, que se encarrega de manter o funcionamento de um órgão que perdeu a capacidade de funcionar por si mesmo.

Apesar da relevância clínica do tema, ainda existem poucas publicações com enfoque na subjetividade na literatura especializada dedicada ao implante de marca-passo, notadamente no contexto latino-americano. A partir de uma busca de artigos empreendida por meio da base eletrônica SciELO, utilizando o unitermo "marca-passo", foram encontradas apenas 23 ocorrências nos últimos 10 anos. Não obstante esse parco resultado, considerando o imenso universo de pesquisas disponíveis no campo das doenças cardíacas, o achado mais surpreendente é que apenas 1 artigo científico elegeu como foco de pesquisa os aspectos psicológicos do paciente, enquanto que os demais focalizavam aspectos biomecânicos e funcionais do mecanismo.

Resultado ainda mais expressivo foi encontrado na consulta à base LILACS: dos 757 registros recuperados a partir do uso do mesmo descritor ("marca-passo"), apenas um referia-se aos aspectos emocionais envolvidos no uso do dispositivo. Frente a essa escassez, são necessárias novas investigações que possam elucidar, particularmente, a percepção das próprias pessoas que convivem com o marco-passo em seu cotidiano. Nessa direção, são bem--vindos os estudos que deem voz aos pacientes, permitindo que eles apreciem o impacto subjetivo de viver com essa condição, o que justifica a presente proposta de investigação, a qual se insere na tradição de pesquisa que preconiza a avaliação em saúde na perspectiva do usuário (Pinheiro \& Martins, 2009).

Feitas essas considerações, este estudo teve como objetivo examinar as percepções do paciente sobre o uso de marcapasso cardíaco permanente.

\section{Método}

Trata-se de um estudo de abordagem qualitativa, do tipo estudo de caso (Triviños, 1987), realizado em um município do interior do Estado de São Paulo. O delineamento qualitativo se mostra apropriado em decorrência das características subjetivas que perpassam o tema e as percepções, que dificilmente seriam apreendidas com a aplicação de instrumentos padronizados, como questionários, escalas ou inventários.

Segundo a literatura, estudos de caso são amplamente utilizados na atualidade, sobretudo por facilitarem a compreensão mais ampla de um determinado fenômeno ao fornecerem insights sobre um assunto ou contestarem uma generalização amplamente aceita (Alves-Mazzotti, 2006; Peres \& Santos, 2005a, 2005b). No presente estudo de caso, buscou-se explorar os significados relacionados às percepções, sentimentos, e pensamentos mobilizados pelo uso do marca-passo cardíaco, relacionando-os ao estado de saúde percebido pela pessoa. Procurou-se, desse modo, delimitar as percepções da própria pessoa entrevistada.

Os requisitos pré-estabelecidos para inclusão de participante na pesquisa foram: ser adulto; ter implantado o marca-passo no mínimo um ano antes do início da coleta de dados, para que fosse possível analisar a repercussão do uso desse dispositivo e seus significados na busca por cuidados; não ter antecedentes de transtorno psiquiátrico; não apresentar dificuldades de compreensão (déficit cognitivo) e/ou de comunicação que pudessem inviabilizar a realização da entrevista.

A participante foi escolhida a partir de uma relação de pacientes cadastrados em uma instituição hospitalar. Desse modo, seguindo critério de conveniência, foi selecionada para participar do estudo Cordélia (nome fictício), 59 anos, que convivia com o marca-passo há quase três anos. A participante é dona de casa e reside em uma cidade do interior paulista. Tem ensino fundamental incompleto, é casada e mãe de três filhos. Desde que teve o mecanismo implantado, a participante tem buscado atendimento no âmbito dos serviços de saúde público e privado.

O primeiro contato com a participante foi estabelecido por telefone. Cordélia prontamente aceitou contribuir com o estudo, mostrando-se solícita ao convite. No dia e hora agendados, a pesquisadora encontrou-se com a participante e, após apresentação mútua, explicou que a entrevista consistia na obtenção de seu relato de como havia sido, para ela, vivenciar o processo de colocação do marca-passo e o que significava essa condição na sua vida atualmente.- 
Para composição do corpus de análise, empregou-se a história de vida focal operacionalizada pela entrevista em profundidade (Bellato et al., 2008), versando sobre a experiência do adoecer, a vivência do processo de implante e as percepções sobre seu uso. A entrevista foi orientada pela questão norteadora: "Conte-me como tem sido sua experiência de conviver com o marca-passo cardíaco, e como isso tem afetado sua vida e a sua família". A partir desse momento, iniciou-se um movimento de construção de uma relação colaborativa entre pesquisadora e participante, que se dispôs a compartilhar sua experiência.

O encontro foi realizado em sala reservada da instituição hospitalar. A entrevista foi audiogravada mediante consentimento da participante e, posteriormente, transcrita na íntegra. Os dados foram complementados por diário de campo.

Para interpretação dos achados, optou-se pela análise de conteúdo das associações verbais obtidas na entrevista, de acordo com os pressupostos da teoria psicanalítica. Considerou-se, na escolha do referencial teórico, a relação histórica entre "doenças do corpo e doenças da alma" (Ávila, 2002) contemplada pela Psicanálise, assim como a aproximação metodológica dessa abordagem com os estudos clínicos de casos individuais.

O presente estudo está amparado nas resoluções éticas que regulam as pesquisas com seres humanos e foi aprovado pelo Comitê de Ética em Pesquisa da instituição de origem da primeira autora, sob protocolo $\mathrm{n}^{\circ}$ 0134/2009. A participação no estudo foi voluntária. Antes do início da coleta dos dados, a participante formalizou sua anuência mediante assinatura do Termo de Consentimento Livre e Esclarecido. Além disso, a coleta dos dados foi efetuada em conformidade com a disponibilidade e motivação da participante. Todos os aspectos éticos foram respeitados. Assegurou-se o direito ao anonimato e a proteção à confidencialidade. Para tanto, foi atribuído um nome fictício para referir-se à participante. Deixou-se em aberto a possibilidade de desistência e retirada do consentimento em qualquer estágio da pesquisa.

\section{Resultados e Discussão}

A leitura aprofundada do corpus proporcionou uma descrição rica e densa acerca das percepções relacionadas ao viver com um marca-passo cardíaco. Por meio dessa leitura, buscou-se delimitar os elementos que evidenciavam tais percepções na história de vida focal, acompanhando suas possíveis modificações ao longo do tempo decorrido desde a colocação do marca-passo.

A participante relatou que, ao passar por uma consulta de rotina com o cardiologista em sua cidade natal, foi encaminhada para um município maior, considerado polo regional em razão de seu nível de desenvolvimento, assim oferecendo maiores recursos e opções de tratamento. Nessa época, Cordélia apresentava sintomatologia bem definida de bradicardia, ou seja, diminuição da frequência cardíaca. "Eu estava sentindo muita ansiedade, muita falta de ar e começou assim de repente. Eu já caminhava já fazia tempo, já fazia uns três anos já que eu caminhava, eu nunca senti nada, de repente, em um dia de manhã, eu comecei a sentir falta de ar".

A indicação médica foi para implantação imediata de marca-passo cardíaco. A semana em que esperou acertar os trâmites da cirurgia foi descrita como "um momento de bastante nervoso e tristeza, principalmente quando eu ficava sozinha. $\mathrm{Eu}$ chorava muito porque eles não estavam aqui. E o doutor me aconselhou, na hora em que ele me viu, que eu não me esforçasse de jeito nenhum". A ansiedade foi agravada pelo medo "de morrer, de chegar uma hora que não tinha mais jeito, de chegar lá no hospital e não dar nada certo, e, na hora, eu ter algum problema grave e acabar morrendo na mesa da cirurgia".

Ao relatar como foi receber a comunicação de que necessitaria colocar o aparelho, Cordélia contou que, inicialmente, ficou "assustada". Sentiu "medo de morrer", temor de não dar tempo de chegar à cidade polo para fazer o procedimento de implantação do aparelho, além de profunda tristeza, principalmente nos momentos em que ficava sozinha. "Eu tinha muito medo de morrer, pensava que eu ia morrer, que não ia ter jeito, que ia acontecer comigo igual aconteceu com meu pai. Na época, eu tinha quase a idade de meu pai também; eu pensava: 'Nossa, o que aconteceu com meu pai vai acontecer comigo"'.

A paciente acreditava que seu problema era hereditário, pois seu pai morrera em decorrência de complicações de uma cardiopatia não tratada ("Meu pai morreu com 50 anos, fazia um mês que eu era casada"). A paciente relatou ter sentido muita tristeza ao ver o pai "chegar morto do trabalho" e que ele tinha conhecimento do problema, mas relutou em colocar o marca-passo, pois tinha medo de morrer durante a realização do procedimento de implantação. Alguns conhecidos do pai haviam passado pelo mesmo procedimento e, depois de um tempo com o marca-passo, acabaram falecendo.

Essa reminiscência fez a participante não hesitar em consentir com a indicação médica, apesar de ter sido pega de surpresa com a urgência do procedimento. A cirurgia foi agendada rapidamente. Durante o procedimento, a paciente foi mantida levemente sedada, porém consciente, como indicado nesse tipo de operação.

Cordélia relata que chorou muito antes de ir para o hospital, mas, em seguida, ameniza o impacto sentido afirmando: "eu sempre fui muito medrosa, como eu comecei a te contar, já é hereditário". A identificação com o problema do pai logo 
se evidenciaria em uma intercorrência ocorrida durante a colocação do aparelho. Ela relata que, no momento do processo cirúrgico, perdeu a visão por seis minutos e pediu para a enfermeira segurar sua mão e rezar o Pai Nosso com ela. O médico orientou que ela ficasse "olhando em um pontinho no teto", que logo a visão iria voltar.

Ele ainda falava: “ta enxergando já, já tá normal?". E eu falava que não, que estava bem embaçado, e foi assim. Então foi voltando devagar, devagar, mas aí eu chorei bastante, eu chorei. Ele até, depois que terminou, me abraçou, falou pra mim ficar tranquila, que já tinha passado, que tava tudo bem, que eu tava bem, e realmente eu fui pro quarto e não senti mais nada, só que eu fiquei assim muito assustada.

A participante atribuiu esse evento adverso à ansiedade. Comentou, mais uma vez, que também vivenciara sentimentos negativos durante o período anterior ao procedimento ("Eu já chorei aqui antes de ir, fui chorando, aí depois cheguei lá e fiquei todo esse tempo").

Para situar e contextualizar o leitor no campo de estudos do inconsciente, é preciso, de início, considerar que o conhecimento produzido sobre o sujeito é singular e não se propõe a generalizações. O que se depreende do modo de funcionamento psíquico de Cordélia diz respeito somente a ela, e não pode servir como referência para outros pacientes que utilizam o marca-passo. Cabe lembrar que o trabalho de significar, pela via da psicanálise, é comparável à tarefa de um arqueólogo: exige disciplina, paciência e um certo tempo de decantação. Os conteúdos simbólicos se associam com os acontecimentos de vida de modo atemporal, sedimentando-se aos poucos por meio de elos e associações complexas. Logo, a tarefa do psicanalista é buscar encontrar sentido e coerência nas associações da paciente, buscando apoio nas formulações teóricas de autores psicanalíticos. As contribuições de Freud (1915/1990a; 1917/1976; 1933/1990b; 1940/1975), Klein (1952/1991), Bion (1978/1992) e Winnicott (1962/1984) são especialmente úteis para a compreensão do padecimento da paciente.

Cordélia, que vivia com um marca-passo havia aproximadamente três anos, declarou-se uma pessoa que continuou a "levar vida normal", como the fora enunciado pelo médico: "tudo normal". Ela afirma que dorme, come e caminha normalmente. Essa sensação de normalidade, ao mesmo tempo em que lhe permite naturalizar o viver com o dispositivo biomecânico, por vezes é problemática, porque ela chega a "esquecer" que utiliza o aparelho, o que a faz, por vezes, deixar de tomar as medicações prescritas. Por outro lado, Cordélia declarou que vivenciara uma série de sentimentos antes do procedimento cirúrgico de instalação do marca-passo, como medo da morte e angústia aguda, agravados pela intercorrência ocorrida na hora em que implantou o aparelho.

O primeiro aspecto a ser ressaltado está ligado ao simbolismo do procedimento médico, considerando-se a possibilidade de controle da vida presente nesse aparelho. Segundo a teoria freudiana, a estruturação do aparelho psíquico compreende uma interrelação entre três instâncias: id, ego e superego. O ego é a instância intermediária entre o mundo interno (id) e o mundo externo (representado no universo psíquico pelo superego). A busca de equilíbrio psíquico depende da possibilidade do sujeito controlar eficientemente seus impulsos e desejos, de modo a assegurar a supremacia do princípio de realidade. O esforço adaptativo põe em marcha um jogo incessante entre as pulsões de vida e de morte, pois o princípio de prazer tentará se impor frente às limitações da realidade e aos constrangimentos impostos pelo ego à gratificação dos impulsos. Para dar conta das demandas pulsionais, o aparelho psíquico precisa lançar mão de alguns mecanismos de defesa inconscientes, como a repressão dos impulsos e sua eventual sublimação. Mas esses recursos defensivos são altamente sofisticados do ponto de vista psíquico, exigindo um grau considerável de evolução e estruturação egóica.

$\mathrm{Na}$ tentativa de manter controle sobre seus conflitos psíquicos, uma saída comumente encontrada pelo sujeito é a produção de sintomas, que são soluções de compromisso entre as moções pulsionais e as forças antagônicas. Isso é possível porque a fantasia e a somatização são destinos comuns para os anseios inconscientes, conforme Freud (1915/1990a) estabeleceu em "Pulsão e seus destinos". Segundo o autor, as associações simbólicas exercem forte descarga pelo órgão somático, enunciando algum significado. Cordélia comentou sobre o período anterior à realização da cirurgia, em que se sentiu mal: "Eu estava sentindo muita ansiedade, muita falta de ar e começou assim de repente [...] Eu tava entrando em menopausa, e todo mês eu menstruava e sangrava muito".

Até esse ponto, pode-se pensar que é plausível a ocorrência de alterações biológicas, uma vez que a menopausa é um período de intensas mudanças hormonais, que desencadeiam sintomas físicos e psicológicos específicos. Contudo, Cordélia fornece um elemento que possibilita avançar um pouco mais na compreensão psicodinâmica de seu padecimento, ao mencionar: "Eu acho que já é um problema que vem acarretando lá de trás [...] meu pai morreu trabalhando, voltou do serviço morto, [pois] meu pai não quis ir operar lá em [nome da cidade]".

Cabe destacar que a coexistência de impulsos de vida e de morte é um postulado fundamental para o processo de entendimento do sujeito pela via da Psicanálise. Esse movimento reiterado de vida-morte, que se desdobra em vivências de prazer-desprazer, é mediado e controlado pelo superego, o qual tem por função estabelecer um funcionamento psíquico de 
acordo com as normas sociais vigentes. Contudo, sendo a constituição psíquica uma formação influenciada por estímulos internos e externos, a rigidez do funcionamento superegóico pode também ocasionar sofrimento, como obsessões, excessiva privação de prazer, auto-recriminação, entre outros sintomas, que levam à perda da espontaneidade e da vitalidade, resultando em um viver sem sentido (Freud, 1915/1990a).

O marca-passo, simbolicamente, pode aludir a esse funcionamento superegóico, com seu teor de castração e privação do prazer. O coração é associado, popularmente, à sensibilidade - um órgão relacionado às emoções e prazeres. Do ponto de vista médico, é uma bomba que pulsa incessantemente, distribuindo oxigênio para todo o corpo e recolhendo o gás carbônico tóxico que resulta das trocas gasosas. O processo de adoecimento começa a ser subjetivado quando é associado a esse órgão um mecanismo artificial, com o propósito de "controlar" o que até então era mantido naturalmente. Isso pode conferir à vida um caráter "desnaturalizado", conforme pontuado na literatura.

"A hora que ele [médico] foi colocar, ele ainda mostrou pra mim, como uma moedinha de um real. Assim, o marcapasso apareceu lá no computador". Cordélia compara o aparelho a uma moeda de um real, fazendo menção ao dinheiro, que é um símbolo contemporâneo de poder e que franqueia o acesso a todo tipo de prazer, como uma promessa de gratificação. Assim, podemos supor que, de fato, seu coração estará "controlado" por algo precioso sentido como externo (superego e suas pressões) à sua mente (ego). Freud (1915/1990a) chamou atenção para um tipo especial de sofrimento a que determinados sujeitos podem se submeter, mesmo que sejam "donas de casa exemplares", em decorrência de fatos mal-elaborados do passado e propulsores de culpa. Embora os clínicos esclareçam que os riscos são mínimos, e que o procedimento de implantação do marcopasso é essencial para a manutenção da vida nas cardiopatias graves, percebe-se um aumento de sintomas depressivos na população que utiliza o marca-passo (Magnani, Oliveira, \& Gontijo, 2007).

Do mesmo modo, frente à morte e ao desconhecido, a fantasia novamente é tomada como meio para elaborar a realidade. Cordélia conta: " $\mathrm{Na}$ hora me deu tanto desespero, que eu pedi pra enfermeira pegar na minha mão e rezar junto comigo, rezar o Pai Nosso". Diante do medo frente ao desconhecido, e com uma percepção de morte iminente, é possível entender que Cordélia projetou na enfermeira a figura de proteção e apoio de que necessitava na hora de máxima aflição.

A perda temporária da visão traz consigo uma evocação da morte, frequentemente associada no imaginário social como cegueira, escuridão, privação de luz ou estado de sono profundo. Conforme pontua Kovács (2008), abre-se espaço, então, para pensar em algum sentimento de culpa ou remorso anterior. O corpo enuncia algo que está na ordem do inconsciente, assim, a solicitação do "Pai Nosso" pode ser vista como remissão/proteção viável dentro de sua capacidade de simbolização e expressão. Pegar na mão da enfermeira foi uma maneira de restabelecer o contato íntimo, "umbilical", com o objeto materno protetor internalizado. Por outro lado, a evocação quase que simultânea do "Pai Nosso" salienta o apelo feito à figura paterna em um momento de máxima fragilidade e desamparo.

Um fator agravante é que Cordélia não havia sido preparada para a possibilidade de sofrer esse dano colateral, tampouco sabia que essa consequência adversa seria reversível, o que reforça o vínculo que ela provavelmente estabeleceu entre a escuridão e a condição de morto do pai - aqui ocupando o lugar daquele que "não vê" o perigo à espreita. Essa equiparação fantasmática (colapso cardíaco - morte do pai - colapso da visão) ela recupera simbolicamente na exortação ao "Pai", que nomeia a oração cristã que passou a entoar em voz alta na mesa de cirurgia. Em suma, é pela figura paterna que ela clama no momento de radical desamparo, como a dizer: "Pai, não estás me vendo?".

Em termos psicodinâmicos, essa questão pode ser compreendida do ponto de vista de um funcionamento esquizoparanoide, atrelado a intenso sentimento de culpa que ativa ansiedade persecutória (Klein, 1952/1991). Nessa linha de raciocínio, o sintoma somático emerge como uma tentativa de projeção maciça da angústia paralisante e cegante, canalizada para o corpo. No caso, pode-se pensar que a "ausência de visão" denotaria o paroxismo da ansiedade decorrente de um luto mal-elaborado ou de um luto que "não foi olhado", observado e experienciado. Um duplo luto, a bem da verdade: pela morte do pai e pela perda de sua condição de saúde, com a instalação da cardiopatia, doença que aproxima Cordélia à condição física que vitimou seu pai.

Seguindo essa linha de raciocínio, é possível enriquecer o entendimento dessa questão ao retomar o preceito de que o inconsciente é atemporal, ou seja, que as pulsões são derivadas de experiências remotas no tempo e que tendem a ser atualizadas no presente (Freud, 1933/1990b). O relato de Cordélia comporta essa leitura, ao enunciar:

Meu pai não quis ir operar lá em [cidade polo], porque tava começando a cirurgia lá e ele falava que tinha muito medo, que naquela época teve um vizinho nosso lá em [nome da cidade natal da participante] que operou do coração e morreu na mesa, justo nos dias que meu pai tava passando mal, e ele falou: "Eu não vou. Vou morrer sem operar, mas lá eu não vou". E morreu mesmo [suspira]. Então, eu acho que já vem aquele... sabe, desde lá de trás eu já tinha aquele medo, e aconteceu comigo a mesma coisa.

A participante evoca a figura do pai como possível "razão" que teria contribuído para a produção de seu sintoma, 
que emerge por identificação ao pai que se recusou a ver, ou seja, que se fez "cego" à sua necessidade de submeter-se ao tratamento, único caminho possível para assegurar sua sobrevivência. Além disso, a figura paterna é trazida mais de uma vez ao longo da entrevista, sendo um elemento significativo dentro de seu discurso.

Como pontuam Magnani et al. (2007), o uso do aparelho marca-passo elucida questões que demandam dos pacientes uma nova organização psíquica ou uma reorganização que lhes permita "viver uma nova vida" com a prótese. Nesse sentido, as experiências prévias de cada indivíduo devem ser olhadas na psicoterapia com um foco essencialmente acolhedor, privilegiando-se a maternagem do paciente (Winnicott, 1962/1984), de modo a favorecer o trabalho de reorganização psíquica.

Pode-se pensar que, em sua dinâmica intrapsíquica, talvez Cordélia sinta-se culpada por não ter podido "salvar" o pai dentro de sua fantasia infantil onipotente. Nesse contexto, pode-se pensar, ainda, em uma associação causal entre a perda do pai (e possível luto mal-elaborado) com o desenvolvimento do sintoma cardíaco na vida adulta. O movimento inercial da pulsão obedece ao princípio da compulsão à repetição. Para Freud (1917/1976), quando o luto não elaborado conduz à melancolia, a sombra do objeto recai sobre o ego.

A "sombra" (falta de luz, perda da visão plasmada em sintoma pela falta de representação simbólica) aponta para a escuridão interna, decorrente da perda precoce do objeto paterno. Na falta de outro recurso para lidar com a moção pulsional, conforme pontuado anteriormente, algumas pessoas acabam por exercer a atuação do impulso diretamente no corpo, sem mediação simbólica, driblando a passagem pelo circuito da linguagem que o modularia. A libido, não sendo apropriadamente elaborada, extravasa para o corpo por não encontrar outras vias de gratificação mais apropriadas. Conforme a própria Cordélia intui, "é porque a gente não tem condição de tá pagando", mas, sem o apoio psicoterápico nesse momento, há um rebatimento sobre o próprio ego. O "estar pagando" associa-se a outro elemento que remete ao dinheiro, que é a moeda. A moeda remete ao controle do coração, e Cordélia vê-se "incapaz" de dar conta do afluxo de energia psíquica mobilizada, o que cria as condições para a produção do sintoma psíquico. Recorda, na mesa de operação, o pai, que não bancou sua "dívida". Lembremos aqui a etimologia do verbo recordar: retornar ao coração.

O "esquecimento" que Cordélia aborda com ênfase na passagem: "mas, de resto, até esqueço que eu tenho marca-passo, porque eu não sinto nada, nada, nada", corrobora, de certo modo, que a negação da realidade está a serviço de alguma demanda inconsciente (Sandler, 2008). Mais adiante, outra fala de Cordélia confirma essa hipótese em que comenta: "eu sempre fui muito medrosa, como eu comecei a te contar, já é hereditário, meu pai morreu com 50 anos". A perda precoce do objeto de amor, tomando o complexo de Édipo como construto central da teoria psicanalítica, acaba por se tornar uma perda do próprio ego, que se identifica com o objeto faltante, acarretando um padecimento, em última instância, do organismo como um todo (Freud, 1915/1990a).

O diagnóstico da cardiopatia e o tratamento prescrito - implante do marcopasso - foi significado como uma ruptura da linha de continuidade do ser, mas no sentido positivo, ou seja, sua qualidade de vida melhorou sob alguns aspectos após o procedimento. Não por acaso a participante relata que o aparelho havia lhe devolvido a vida, pois seus batimentos cardíacos, antes da cirurgia de implante, estavam abaixo da média, cerca de 30 por minuto, sendo que o normal é de 90 a 110 batimentos por minuto. $\mathrm{O}$ déficit cardíaco causava uma série de sintomas que a impossibilitavam de trabalhar e de realizar suas atividades de vida diária.

Ah, depois que eu coloquei, nossa, parece que eu revivi, sou outra pessoa, porque nunca mais eu tive... Agora, o único medo que eu tenho, que, no entanto, eu procuro me cuidar o mais que eu posso... o doutor fala que eu não posso ganhar peso. [...] $\mathrm{O}$ único medo que eu tenho agora é disso, tornar a se agravar e ter que fazer aquela cirurgia de pôr ponte de safena, aquelas coisas; eu morro de medo de fazer aquelas outras cirurgias.

Recapitulando, a paciente conta que chegou à consulta médica "quase parando", "sem pulso", foi surpreendida (o que poderia ser diferente, se houvesse levado em consideração o histórico familiar) com o diagnóstico e a indicação de marcapasso. Após submeter-se ao procedimento, foi tranquilizada pelo cardiologista de que iria ter uma "vida normal" dali por diante. A partir desse evento crítico, como seria conviver com a anormalidade, tendo uma vida "normal"?

Ao contar sobre como estava sendo, para ela, fazer uso do marca-passo, a participante respondeu que não tinha problema algum, exceto nos afazeres domésticos e na ginástica, atividades nas quais se sentia um pouco mais cansada. Não referiu alterações mais drásticas em seus hábitos de vida, como referido na literatura (Brasil \& Cruz, 2000), nem se queixou das repercussões do autocuidado em seu estilo de vida pós-implante (Falcão, 2004). Relatou que o médico, ao lhe oferecer as orientações pós-cirúrgicas, disse que ela poderia ter vida normal. Deveria apenas ser cautelosa em relação aos esforços físicos.

Mas é o único probleminha que eu sinto, mais nada. Normal, minha vida normal; tenho tudo normal: durmo normal, como 
normal, caminho normal. Caminho todos os dias. Agora eu estou participando dessas atividades que eu te falei, dessas ginásticas, né, também tudo normal. Tenho, às vezes, quando a professora força um pouquinho, eu sinto um pouquinho de cansaço e eu dou aquela paradinha, aí retomo novamente.

Em relação à família, Cordélia refere ter recebido muito carinho, atenção e amor, já que todos ficavam à sua volta incentivando-a a ir com fé, porque tudo daria certo. Ela afirma que até hoje os familiares "ficam em cima" dela, porque muitas vezes ela esquece de comprar o remédio de uso diário quando acaba. Os filhos "ficam bravos": "Mãe, você não pode deixar acabar. Por que você não fala, você vai buscar você pede pro pai, ou, então, você pede pra gente?".

Por outro lado, contribuindo para agravar seus sentimentos de desamparo e menos valia, Cordélia relata que tem medo de que os filhos não possam cuidar dela, o que sugere sentimentos ambivalentes que ela projeta nos familiares. Ora, se ela tem a fantasia de que teve culpa pela extinção de seu objeto de amor (pai), em decorrência de ele ter negligenciado sua falência cardíaca, pode projetar nos filhos sentimentos semelhantes, possivelmente em decorrência de não ter um claro discernimento acerca do conteúdo recalcado. Assim, utilizando de mecanismos como a identificação projetiva, Cordélia acaba expressando suas angústias sob a forma de sintomas.

Uma das consequências de "ter tudo normal" e "não estar sentindo nada", quando se refere ao problema cardíaco, é o esquecimento de tomar os medicamentos prescritos. Os filhos, alarmados, tentam modificar o comportamento da mãe, permanecendo hipervigilantes em relação aos horários dos remédios. Esquecer-se de tomar os medicamentos de uso diário é uma forma de tornar-se visível, isto é, de fazer com que os filhos a vejam em seu mudo padecimento. Outra hipótese plausível é a de que Cordélia boicota a medicação para "culpar" os filhos e, assim, não precisar olhar para o seu próprio "fracasso" enquanto filha que não pôde deter a morte do pai. Possivelmente por isso se faz cega.

Bion (1978/1992) diria, a respeito dessas manifestações emocionais, que o desejo de evitar o confronto com a verdade, que, no caso de Cordélia, poderia ser um sentimento de culpa por "não ter cuidado" e protegido o pai, tem como objetivo evitar o contato com a dor. Para Klein (1952/1991), em uma situação de frustração e inibição intensa do prazer, o indivíduo pode apresentar dois destinos básicos. O primeiro deles é a melancolia ou depressão, em que predomina uma sensação de impotência diante do mundo mau e adverso. No segundo, a voracidade do desejo projeta-se no objeto amado, o que alimenta a condição de posição esquizoparanoide. Nessa última, há uma dose de indistinção entre eu e não eu, que também está a serviço de encobrir as verdadeiras razões do padecimento.

Desse modo, constata-se a força com que o inconsciente expressa sua energia reprimida. Tomando por base que a pulsão exige descarga imediata, a participante, alheia aos seus conteúdos inconscientes, elege o corpo como via privilegiada de expressão dos conflitos.

De acordo com Magnani et al. (2007), a aceitação do marca-passo é percebida de forma singular por cada pessoa. Assim, é possível observar características semelhantes no comportamento dos portadores, pois o implante significa conectar sua vida a um aparelho, sendo o coração significado como fonte de vida. Ainda segundo esses autores, após a colocação do marca-passo, a pessoa muda completamente seu estilo de vida, sendo induzida a elaborar estratégias e rituais que vão muito além dos cuidados recomendados pelos médicos. Em outras palavras, os pacientes tendem a executar suas atividades com excesso de zelo e meticulosidade, o que parece indicar que essas preocupações estão relacionadas muito mais às ideias, mitos, fantasias e sentimentos dessas pessoas do que aos perigos concretos suscitados pelo procedimento cirúrgico ou pela convivência com o dispositivo.

Assim como acontece em pacientes acometidos por outras doenças crônicas, vivencia-se uma transição entre o estado de saúde, do qual a pessoa desfruta antes de ter a patologia aparente, e o recebimento do diagnóstico de uma condição que ameaça a continuidade da vida. Essa passagem para o ser-doente leva o paciente a ter que ressignificar e reconstruir o sentido de sua existência, pois têm que lidar com a perspectiva de morte ao ver extinguir a fantasia de imortalidade (Magnani et al., 2007). No caso de Cordélia, chama atenção justamente sua insistência na manutenção da "mesma vida de antes", exceto por estar mais cuidadosa com a alimentação e por se sentir fatigada após atividade física mais intensa. É importante para a paciente reiterar que nada mudou e que a vida segue seu curso normal, ou seja, ela reluta em se ver na condição de doente.

Diante do exposto, pode-se colocar em discussão o papel desempenhado pelo profissional de psicologia junto às equipes multidisciplinares que atendem esses casos. Os pacientes que necessitam do marca-passo para continuarem vivendo provavelmente não apresentarão um drama humano exatamente idêntico ao de Cordélia. É igualmente improvável que estabeleçam as mesmas correspondências entre vivências psíquicas e sintomatologia. Contudo, o processo de simbolização e atribuição de significados diversos à experiência vivida é uma característica inerente ao ser humano. Caberia ao psicólogo intervir nesse nível, auxiliando o paciente a refletir sobre os significados outorgados às suas experiências de conviver com o implante cardíaco.

Assim, conforme evidenciado na literatura, "nada do que um paciente fala na sessão é isento de função, que pode ser detectada e submetida à reflexão e comunicação" (Sandler, 2008, p. 43). Pode-se pensar que, para o sujeito doente, existe 
uma alternativa que não o padecimento psíquico. Tal como postula Winnicott (1962/1984), o sujeito, mesmo assumindo uma posição onipotente frente ao que lhe causa o sintoma (conteúdo inconsciente), pode simbolizar e representar de outro modo sua vida, em uma perspectiva mais adaptativa e favorável do ponto de vista psíquico.

Em seu estudo, Brasil e Pondé (2009) comentam que a associação entre transtornos mentais e doenças físicas se deve tanto a fatores psicossociais quanto biológicos. "Dentre os primeiros, ressaltam-se a frustração na realização de desejos e necessidades, agravamento de conflitos intrapsíquicos, inadequação dos mecanismos de defesa, perda do sentimento de autoestima, alteração da imagem corporal e isolamento social" (p. 24). A respeito disso, percebe-se que a história de Cordélia ilustra com relativa precisão a questão da formação de sintomas e da inadequação dos mecanismos de defesa utilizados. No caso, a culpa inconsciente pelo falecimento do pai quase arrastou a paciente ao encontro do mesmo destino que o surpreendera, ou seja, a morte prematura. Cordélia reapresentou a mesma necessidade de seu pai ao demandar um marca-passo cardíaco. Freud dizia que o sintoma representa algo anterior, que jaz enraizado no psiquismo, o que permite ampliar a análise dessa questão propiciando pensar sobre as diferentes etiologias das doenças. O pai de Cordélia morreu por recusar se submeter à cirurgia de implante do aparelho que supostamente poderia salvá-lo. Em outros termos, morreu por ter ficado paralisado pelo medo de morrer. Anos depois, a paciente se depara com a mesma necessidade, o que lhe mobilizou intensamente, desencadeando um período de extrema ansiedade, medo e proximidade com a morte. Ademais, mostrando-se sensível ao legado transmitido por herança transgeracional, ela atribui a uma "causa hereditária" o medo extremo que sentiu quando a doença se manifestou abruptamente.

Esse "encontro" drástico com os conteúdos inconscientes foi de tamanha intensidade emocional que Cordélia uma vez mais se valeu do recurso de que dispunha no momento, que era o ato do "esquecimento". A "amnésia", assim como a perda da visão, torna-se evidência contundente da não capacidade de compreender a realidade (Chavatal, Böttcher-Luiz, \& Turato, 2009), o que é compreendido pelo cirurgião de modo distinto quando disse à paciente que isso logo iria passar, em uma perspectiva que tanto desconsidera a história da paciente como a interpreta dentro de um modelo restrito. Por outro lado, a identificação de Cordélia com uma situação adversa ocorrida no passado (perda do pai em situação similar a que se encontrava naquele momento) denota a "ambivalência do devir humano e a força dos conteúdos inconscientes" (Klein, 1952/1991, p. 283).

Uma forma de organização dos conteúdos mobilizados é o engendramento do sintoma, que está atrelado a uma experiência angustiante latente, eliciada quando a paciente se encontrava na mesa de cirurgia. Esse caso ilustra a relevância de se garantir um processo de escuta dentro de unidades cardiológicas, junto aos pacientes com suas variadas demandas. $\mathrm{O}$ caso analisado sugere que essa escuta qualificada e diferenciada, embora não seja exclusiva do psicólogo ou do psicanalista, requer um preparo específico no manejo e interpretação dos fenômenos inconscientes (Santos, 2007).

É pertinente pontuar que, embora a leitura empreendida explore questões sob o amparo da Psicanálise, diversos estudos de delineamento mais descritivo corroboram a tese explorada no presente estudo. Sardinha et al. (2009) avaliaram de modo sistemático as publicações em cardiologia que tratam do impacto dos estados psicológicos na saúde cardiovascular. Na análise das publicações revisadas, os pesquisadores encontraram que condições psicológicas adversas, tais como ansiedade e depressão, apresentam relação direta com as doenças cardiovasculares. Embora a maior parte dos estudos não se volte para uma "interpretação" do conteúdo inconsciente da doença, nem postule possíveis causas psíquicas do sofrimento, as discussões apontam para a necessidade de intervenção psicoterapêutica de modo a prevenir agravos ou até mesmo evitar que se elicie a doença cardiovascular nesses casos.

\section{Considerações Finais}

No presente estudo, a abordagem por meio da entrevista aberta permitiu compreender como Cordélia vivencia sua condição de saúde após o implante de marca-passo cardíaco permanente. Mais especificamente, propiciou elucidar quais são suas percepções acerca da colocação desse dispositivo e da contingência de ter de conviver com esse mecanismo biomecânico pelo resto da vida. As percepções prevalentes foram: choque ao receber o diagnóstico, medo de morrer durante a cirurgia, implante do marca-passo como tábua de salvação, satisfação com o procedimento, e preocupação constante dos familiares com o bem-estar da paciente.

Ao direcionar o olhar para as dimensões psíquicas envolvidas no uso do mecanismo cardíaco, dados epidemiológicos advindos de estudos na área apontam para uma elevada prevalência de sintomas psicológicos, como ansiedade e depressão (Leosdottir et al., 2006; Magnani, Oliveira, \& Gontijo, 2007; Newall et al., 2007). Na literatura médica existe um consenso de que tais alterações aumentam consideravelmente a possibilidade de desenvolvimento ou agravo de outras patologias, dentre as quais se situam as doenças cardiológicas, o que justifica investigar psicanaliticamente esses quadros, de modo a contribuir para a instrumentalização de serviços de saúde capazes de atender às diversas demandas do paciente, desde as 
mais concretas e objetivas até as de ordem subjetiva.

Algumas perguntas puderam ser formuladas no decorrer da elaboração deste estudo, dentre elas: Quais são os mecanismos psíquicos de defesa que perpassam a aceitação do procedimento cirúrgico de implantação definitiva de um implante cardíaco? Que fantasias inconscientes emergem no paciente que necessita de tal procedimento para prolongar sua vida? E que medidas e recursos de apoio psicológico no âmbito da atenção em saúde podem ser promovidos de modo a atenuar o padecimento psíquico nesses casos? Para dialogar com esses questionamentos, recorreu-se a uma compreensão teórica do caso a partir da análise da entrevista realizada. Nesse processo, efetuado a partir de uma leitura psicanalítica, foram abordados tópicos elucidativos que guiaram a compreensão dos investigadores, porém há limitações metodológicas que devem ser ponderadas.

Partindo de um estudo de caso específico, no qual não cabem generalizações, foi possível apreender que o processo de simbolização e atribuição de significados diversos à experiência do adoecimento é uma característica inerente ao ser humano, o que merece a atenção da equipe de saúde para que os fatores emocionais sejam incluídos nos cuidados em saúde. A riqueza das narrativas fez emergir a subjetividade da paciente, as interpretações e sentidos que ela pôde tecer ao vivenciar o processo saúde-doença-cuidado, possibilitando uma compreensão profunda de suas vivências. Futuros estudos são necessários, com novos delineamentos metodológicos, abarcando a diversidade de situações encontradas na prática clínica.

Considerando a necessidade de uso de marca-passo um fator frequentemente associado ao aumento de sofrimento psicológico, e sendo consenso que esse estado conduz, muitas vezes, ao agravamento da doença de base, a indagação reflexiva que fica é: Não seria sensato prover a acolhida aos aspectos emocionais como um dos recursos para evitar que outros pacientes "deixem de ver", tal como Cordélia e seu pai? Nas análises destacaram-se a falta de familiaridade da paciente em relação aos seus mecanismos somatizadores, em termos de sua importância e consequências geradas, assim como o desconhecimento da equipe multiprofissional, que interpretou sua cegueira provisória apenas como sinal de ansiedade, em um total desconhecimento da história de vida da paciente. Tal desconsideração é reflexo da ausência de escuta diferenciada, que acaba alimentando sentimentos de inquietação, medo e angústia da paciente, os quais podem alterar profundamente seu relacionamento interpessoal e intrapsíquico.

É mister que consideremos que o sujeito saudável participa e está engajado em seu próprio processo de promoção de saúde. A equipe de saúde, por sua vez, deve ser alertada sobre a pertinência de ações com foco mais primário e preventivo, promovendo espaços e momentos nos quais os profissionais possam não apenas acolher o paciente em suas angústias, mas também discutir coletivamente com outros saberes os limites, alcances e necessidades do fazer profissional no contexto do uso do marca-passo. Nessa vertente, a compreensão psicanalítica apresentada neste estudo fornece alguns subsídios para o aprimoramento das práticas de gestão e cuidado de pacientes que convivem com a realidade do implante de marca-passo cardíaco permanente

\section{Referências}

Alves-Mazzotti, A. J. (2006). Usos e abusos dos estudos de caso. Cadernos de Pesquisa, 36(129), 637-651.

Andrade, J. C. S. (2001). Técnicas cirúrgicas para implante de marcapasso. In J. C. S. Andrade et al. (Orgs.), Temas de marcapasso (pp. 85-119). São Paulo: Lemos.

Aredes, A. F., Lucianeli, J. G., Dias, M. F., Bragada, V. C. A., Dumbra, A. P. P., \& Pompeo, D. A. (2010). Conhecimento dos pacientes a serem submetidos ao implante de marcapasso cardíaco definitivo sobre os principais cuidados domiciliares. Revista Latino-Americana de Marcapasso e Arritmia, 23(1), 28-35.

Ávila, L. A. (2002). Doenças do corpo e doenças da alma. São Paulo: Escuta.

Bellato, R., Araújo, L. F. S., Faria, A. P. S., Santos, E. J. F., Castro, P., Souza, S. P. S., . . Maruyama, S. A. T. (2008). A história de vida focal e suas potencialidades na pesquisa em saúde e em enfermagem. Revista Eletrônica de Enfermagem, 10(3), 849-856. Retirado de: $<$ http://www.fen.ufg.br/fen_revista/v10/n3/pdf/v10n3a32.pdf>.

Benassi, M. D., Valero, E., \& Jurado, L. (2009). Efeito dos aparelhos iPod e MP4 sobre o funcionamento dos marcapassos. Revista Latino-Americana de Marcapasso e Arritmia, 22(3), 120-124.

Bion, W. (1992). Quatro discussões com W. R. Bion. In W. Bion. In Conversando com Bion. Rio de Janeiro: Imago. (Obra 
original publicada em 1978)

Brasil, I. S. P. S., \& Pondé, M. P. (2009). Sintomas ansiosos e depressivos e sua correlação com intensidade da dor em pacientes com neuropatia periférica. Revista de Psiquiatria do Rio Grande do Sul, 31(1), 24-31.

Brasil, V. V., \& Cruz, D. A. L. M. (2000). Alterações nos hábitos de vida relatadas por portadores de marcapasso definitivo. Revista Latino-Americana de Marcapasso e Arritmia, 13(2), 97-113.

Carroll, D. L. (2014). Antecedents to the integration process for recovery in older patients and spouses after a cardiovascular procedure. International Journal of Nursing Practice, 20(1), 97-105.

Chavatal, V. L. S., Böttcher-Luiz, F., \& Turato, E. R. (2009). Respostas ao adoecimento: Mecanismos de defesa utilizados por mulheres com síndrome de Turner e variantes. Revista de Psiquiatria Clínica, 36(2), 43-47, 2009.

Falcão, P. V. (2004). Repercussão do autocuidado no estilo de vida do portador de marcapasso. Dissertação de Mestrado não-publicada, Centro de Ciências da Saúde da Universidade de Fortaleza, Fortaleza, CE.

Freud, S. (1975). Esboço de psicanálise. In J. Strachey (Ed.), Edição Standard Brasileira das Obras Completas de Sigmund Freud (Vol. XXIII). Rio de Janeiro: Imago. (Obra original publicada em 1940)

Freud, S. (1976). Luto e melancolia. In J. Strachey (Ed.), Edição Standard Brasileira das Obras Completas de Sigmund Freud (Vol. XIV). Rio de Janeiro: Imago. (Obra original publicada em 1917)

Freud, S. (1990a). Os instintos e suas vicissitudes. In J. Strachey (Ed.), Edição Standard Brasileira das Obras Completas de Sigmund Freud (Vol. X, $3^{\mathrm{a}}$ ed.). Rio de Janeiro: Imago. (Obra original publicada em 1915)

Freud, S. (1990b). Novas conferências introdutórias à psicanálise. In J. Strachey (Ed.), Edição Standard Brasileira das Obras Completas de Sigmund Freud (Vol. XXII, $3^{\mathrm{a}}$ ed.). Rio de Janeiro: Imago. (Obra original publicada em 1933)

Klein, M. (1991). Inveja e gratidão e outros trabalhos (E. M. da Rocha \& L. P. Chaves, Trads.). Rio de Janeiro: Imago (Obra original publicada em 1952)

Kovács, M. J. (2008). Morte e existência humana: Caminhos de cuidado e possibilidades de intervenção. Rio de Janeiro: Guanabara Koogan.

Leão, M. I. P. (2001). Normas para orientação de pacientes portadores de marcapasso. In J. C. S. Andrade et al. (Orgs.), Temas de marcapasso (pp. 183-198). São Paulo: Lemos.

Leosdottir, M., Sigurdsson, E., Reimarsdottir, G., Gottskalksson, G., Torfason, B., Vigfusdottir, M., ... Arnar, D. A. (2006). Health-related quality of life patients with implantable cardioverter defibrillators compared with that of pacemaker recipients. Europace, 8, 168-174.

Magnani, C., Oliveira, B. G., \& Gontijo, E. D. (2007). Representações, mitos e comportamentos de pacientes chagásicos com marcapasso. Cadernos de Saúde Pública, 23(7), 1624-1632.

Martinelli Filho, M., Zimerman, L. I., Lorga, A. M., Vasconcelos, J. T. M, \& Rassi, A. Jr. (2007). Diretrizes brasileiras de dispositivos cardiacos eletrônicos implantáveis (DCEI), 89(6), e210-e238.

Mello Filho, J. (1992). Psicossomática hoje. Porto Alegre, RS: Artes Médicas.

Newall, E. G., Lever, N. A., Prasad, C., Hornabrook, C., \& Larsen, P. D. (2007). Psychological implications of ICD implantation in a New Zealand population. Europace, 9, 20-24.

Oliveira-Cardoso, E., Santos, M. A., Mastropietro, A. P., \& Voltarelli, J. C. (2009). Qualidade de vida de sobreviventes do 
transplante de medula óssea (TMO): Um estudo prospectivo. Psicologia: Teoria e Pesquisa, 25(4), 529-536.

Peres, R. S., \& Santos, M. A. (2005a). Considerações gerais e orientações práticas acerca do emprego de estudos de caso na pesquisa científica em Psicologia. Interações: Estudos e Pesquisa em Psicologia, 10(20), 109-126.

Peres, R. S., \& Santos, M. A. (2005b). Sobre a elaboração e utilização do estudo de caso na pesquisa científica e na prática profissional em Psicologia. In C. P. Simon, L. L. Melo-Silva, \& M. A. Santos (Orgs.), Formação em Psicologia: Desafios da diversidade na pesquisa e na prática (pp. 117-130). São Paulo: Vetor.

Pinheiro, R., \& Martins, P. H. (Orgs.) (2009). Avaliação em saúde na perspectiva do usuário: Uma abordagem multicêntrica. Rio de Janeiro: IMS: Abrasco; Recife: Editora Universitária UFPE.

Sandler, P. C. (2008). Freie Einfälle: A irrupção verbal do desconhecido. Revista Brasileira de Psicanálise, 42(2), 43-57.

Santos, M. A. (2007). Psicoterapia psicanalítica: Aplicações no tratamento de pacientes com problemas relacionados ao uso de álcool e outras drogas. SMAD: Revista Eletrônica Saúde Mental Álcool e Drogas, 3(1). Recuperado em 15 agosto, 2015, de http://pepsic.bvsalud.org/pdf/smad/v3n1/v3n1a06.pdf

Sardinha, A., Nardi, A. E., \& Zin, W. A. (2009). Ataques de pânico são realmente inofensivos? O impacto cardiovascular do transtorno de pânico. Revista Brasileira de Psiquiatria, 31(1), 57-62.

Triviños, A. (1987). Introdução à pesquisa em ciências sociais: A pesquisa qualitativa em educação. São Paulo: Atlas.

Van-Eck, J. W., Van-Hemel, N. M., Kelder, J. C., Van-der-Bos, A. A., Taks, W., Grobbee, D. E. . . Moons, K. G. (2008). Poor health-related quality of life of patients with indication for chronic cardiac pacemaker therapy. Pacing and Clinical Electrophysiology, 31(4), 480-486.

Watkins, E. \& Brown, R. G. (2002). Rumination and executive function in depression: An experimental study. Journal of Neurology, Neurosurgery \& Psychiatry, 72, 400-402. DOI: http://dx.doi.org/10.1136/jnnp.72.3.400

Willians, A. M., Young, J., Nikoletti, S., \& McRae, S. (2004). Reasons for attending and not attending a support group for recipients of implantable cardioverter defibrillators and their careers. International Journal of Nursing Practices, 10(3), 127-133.

Winnicott, D. W. (1984). Os objetivos do tratamento psicanalítico. In D. W. Winnicott, O ambiente e os processos de maturação (I. C. S. Ortiz, Trad.). Porto Alegre, RS: Artes Médicas (Obra original publicada em 1962)

\section{Endereço para correspondência}

Manoel Antônio dos Santos

End.: Faculdade de Filosofia, Ciência e Letras de Ribeirão Preto da Universidade de São Paulo Avenida Bandeirantes, 3900, Monte Alegre, Ribeirão Preto, SP, CEP 14040-901.

E-mail: masantos@ffclrp.usp.br 